\title{
Tourism Ecolabels and Social Sustainability: Challenges and Innovations from a Slovene Perspective
}

\author{
Vinod Sasidharan \\ San Diego State University, USA \\ vsasidhar@mail.sdsu.edu \\ Dejan Križaj \\ University of Primorska, Slovenia \\ dejan.krizaj@fts.upr.si
}

To gain new insights regarding the implementation of social sustainability practices, this study examined the sustainability performance of five tourism businesses in Slovenia. Each of the five has been awarded the Slovenia Green Certificate or a national award for innovative achievements (Sejalec, Snovalec) by the Slovenian Tourist Board. Semi-structured interviews were conducted among the tourism providers based on environmental, social, and economic dimensions. Findings from the study can help in the stimulation and achievement of higher levels of social sustainability performance within Slovenia's growing tourism industry while positioning the country as not only a green tourism leader but also as a socially-responsible destination.

Keywords: social sustainability, ecolabels, innovation, Slovenia https://doi.org/10.26493/2335-4194.11.19-29

\section{Introduction}

Emerging tourism destinations can play a globally significant role in championing the adoption of sustainable tourism development, and in setting the stage for other destinations to follow. The implementation of sustainability practices within tourism settings will be crucial for a destination's enhanced tourism competitiveness, tourist brand loyalty, corporate social responsibility among tourism organizations, innovation, and overall community and economic well-being (Lai, Chiu, Yang, \& Pai, 2010). In recent years, destinations as a whole, as well as private enterprises and public entities within the tourism industry have become increasingly responsive to new societal priorities associated with sustainable development and the surging demand among tourists for sustainable experiences, including products and services, which are ecologically and socially responsible (Chatterji \& Toffel, 2010). This trend has provided emerging tourism destinations with the opportunity to develop tourism amenities, attractions, and facilities, while directly responding to the growing awareness among tourists regarding the benefits of sustainable development and their increasing propensity to purchase tourism products and services from enterprises with a proven track record of promoting sustainability through their dayto-day operations. As a result, there has been significant growth in tourism enterprises and organizations offering 'green' experiences to tourists (Vaccaro \& Patiño, 2010) since the mid-199os.

'Green' assertions made by tourism establishments are often unverifiable due to the lack of clear government policies and industry regulations for monitoring the alignment of the marketing rhetoric used 
in juxtaposition with the actual sustainability performance of the enterprises claiming to be environmentally and socially conscious in their practices. Tourism enterprises, organizations and, suppliers have the potential to capture a significant proportion of the international tourism market share by educating and directing the industry regarding ways to go beyond mere 'green' rhetoric (Sandhu, Ozanne, Smallman, \& Cullen, 2010; $\mathrm{Wu}, 2010)$. Within the last two decades, there has been an exponential increase in various voluntary ecolabeling/eco-certification schemes and CSR assessment programs for verifying the ecological and social responsibility claims of tourism businesses (Font, 2002) and for recognizing sustainability leaders within the tourism marketplace (Buckley, 2013). Globally, more than one hundred eco-certifications for tourism organizations are currently available (Dziuba, 2016), and half of these schemes are specific to the tourism industry of the European Union (Margaryan \& Stensland, 2017).

Tourism ecolabeling schemes provide certificates, plaques, trademarks, or logos to those tourism enterprises that either meet or supersede the sustainability parameters and performance metrics established by the certifying organization (Margaryan \& Stensland, 2017). Generally, tourism ecolabels are awarded to an enterprise after a voluntary third-party audit/assessment of the institution's sustainability practices is conducted (Honey \& Rome, 2001). Following this step, a written statement of assurance and/or a marketable 'seal of approval' is issued by the certifying body to promote the environmental achievements of the company and to generate a positive image and goodwill among tourists regarding the organization (Middleton \& Hawkins, 1998). From a marketing perspective, an ecolabel serves as a tool for a tourism enterprise to distinguish itself from competitor(s) based on a thirdparty endorsement of its superior sustainability performance - the ecolabels are displayed by tourism enterprises both onsite and through web-based and print media channels to highlight their sustainability accomplishments to tourists and stakeholders (Morgan, 1999). In addition, tourism ecolabels encourage the adoption of sustainability practices among both private and public sectors of the travel industry, thereby stimulating the creation of innovative and organic solutions (through products and services) for addressing sustainability issues and for mitigating the adverse environmental, social, and economic outcomes of their operations through improved sustainability performance (Mihalic, 2000).

Although the predominant focus of tourism ecolabels is on the environmental performance of organizations, most schemes also include metrics and indicators for evaluating social sustainability practices, beyond compliance with ecological and economic guidelines. The general criteria (Dawkins, 2010) employed by most tourism ecolabeling agencies for assessing the sustainability performance of organizations are: environmental responsibility (improvement of air, water, and soil), pollution control and prevention (management, reduction, prevention, reuse and recycling of materials, including paper and waste), energy conservation (use of solar, wind, water, geothermal, and biofuel energy sources), water conservation (water efficiency, reduction and/or elimination of the amount of water required to do business), education (encouragement of employees, suppliers, and tourists to practice environmental responsibility and sustainability), community initiatives (sponsorship, development or support for community, educational, civic, or industryrelated initiatives), and socio-cultural impact (management, preservation and stewardship of cultural and natural heritage). Despite the availability of several commonly used measures for the assessment of environmental and economic performance within the tourism industry, to our knowledge, there is a lack of reliable measurement outlines to evaluate the social sustainability practices and outcomes of tourism organizations. Although ecolabels provide tourism enterprises with a platform to attract travelers through the promotion of products and services that cater to their sustainability preferences and demands, it should be noted that the majority of eco-certified organizations demonstrate higher sustainability standards and achievement levels in the areas of environmental and economic performance, compared to lower levels of accomplishments in the social criteria for sustainability, chiefly due the lack of proper guidelines and indicators for social sustainability performance 
among current tourism ecolabeling schemes (Sasidharan, 2017).

Underperformance in the social component of sustainability among eco-certified tourism enterprises can be attributed to the ethical obligation perceived by tourism managers (Sandve, Marnburg, \& Ogaard, 2014) regarding the extent to which 'unclear' social sustainability parameters need to be met as opposed to the 'clearly' articulated environmental performance guidelines identified by ecolabeling schemes. In order to better understand the challenges associated with the implementation of social sustainability practices among eco-certified enterprises with the tourism industry, this study examined the sustainability performance of five tourism businesses in Slovenia; each of the five has been awarded the Slovenia Green Certificate by the Slovenian Tourist Board (зтв) or the national award for innovative achievements. Findings from the study can be employed by the s т в to stimulate the achievement of higher levels of social sustainability performance within Slovenia's growing tourism industry while positioning the country as not only a green tourism leader but also as a socially-responsible destination.

\section{Background}

Slovenian tourism recorded a 9 per cent increase in tourist arrivals in 2016 and 8 per cent more overnight stays than in 2015, reaching the limit of 11 million overnight stays. With 11 per cent more foreign tourist arrivals and 10 per cent more foreign overnight stays in 2016, it is ranked above the European and global average (Slovenian Tourist Board, 2017). The sт в also estimates that the 2017 inflows from exports of travel will reach new record numbers, as the growth of exports of travel for the first eleven months of 2016 is 4 per cent. Findings suggest tourism is an increasingly important industry in Slovenia, with potential for further growth, currently contributing close to 13 per cent to the gross social product, accounting for 8 per cent of total exports and 37 per cent of exports of services (Slovenian Tourist Board, 2017). With the expected evolvement and several green characteristics (for instance, relative forest coverage in E $\mathrm{U}$ puts Slovenia in the third place, following Finland and Sweden), green tourism became a necessary direction for the S тв, which has committed itself to be green and sustainable (see http://www.slovenia.info/zelenashema). The sтв's mission in green tourism is to inform stakeholders about the tourism impacts and to encourage actions in adapting and mitigating climate change. Among their key strategic orientations are the green economy, incentives to develop green business models and sustainable development models, and sustainability awareness raising among tourists.

To support the represented results, outlooks and orientations, the Green Scheme of Slovenian Tourism (GSST) has been developed. The GSsT enables international comparison of Slovenian tourism and facilitates the positioning of green Slovenia globally. In 2015, following several developments and national coordination steps, GSST was applied to the tourism industry level in partnership between the sтв, GoodPlace (a Slovenian private R \& D institute), and Green Destinations (a non-profit organization for sustainable tourism with headquarters in the Netherlands). The sтв manages and develops the GssT, offers educational support, and (most importantly) establishes international marketing channels for the promotion of destinations and tourism providers with the Slovenia Green certificate. GoodPlace is the accredited GSsT partner with a license to issue certificates in accordance with the global Green Destinations' tool.

Gss T's Slovenia Green certification/standard is based on the Green Destinations standard, created in cooperation with the European Centre for Eco and Agro Tourism, the Coastal \& Marine Union, and the Global Sustainable Tourism Council. For tourism destinations, the certification process runs through a dedicated online platform, where they self-assess their sustainable management and policies, obtain feedback from consultants and the auditor, and receive a final assessment of sustainability. For tourism providers, the process is not run in-house, but there are six internationally recognized certificates, which when obtained automatically earn them the Slovenia Green certificate. Similarly, there are two international certificates that are valid for nature parks.

When a tourism destination enters the certification process, it follows 11 steps (see http://www.slovenia 
.info/zelenashema): 1. Definition of the Green Coordinator, 2. Creating a Green Team, 3. Increasing awareness, getting support, 4. Signing a Green Policy, 5. Surveying destinations' stakeholders and resources, 6. Collecting and inputting data into the online platform, 7 . Submitting the report and the request for assessment, 8. Preparing and approving the Action Plan, 9. Defining the local character and green unique selling points, 10. Submitting a field visit application, and 11. Implementing measures and reassessment. The certification costs vary: for destinations they amount to $€ 1,220$ plus VAT, for tourism providers and parks the cost is €100 plus vat.

The Slovenia Green certification scheme comprises 100 criteria and 147 indicators, summarized according to the Green Destinations and Global Sustainable Tourism Council standards. The criteria are divided into six themes: Destination Management, Nature and Landscape, Environment and Climate, Culture and Tradition, Social Climate, and Tourism Business. Destinations are graded on a scale of 1 to 10 and receive three types of Slovenia Green Destination certificates (gold, silver, bronze), according to their score. Thus far, the Slovenia Green certificates have been granted to 22 tourism destinations, 13 accommodation providers, three nature parks, and two tourism agencies.

The sтв sees orientation to sustainable development as 'the only real development opportunity' for Slovenia and its tourism offerings, aiming for the development of high quality and innovative tourism products (see http://www.slovenia.info/zelenashema). Therefore, in the certification process, destinations and providers sign the Green Policy of Slovenian Tourism, expressing the fundamental commitment to operate according to sustainability principles and to continuously strive for improvements. The certificate brings further advantages to its recipients in terms of raising visibility and promotion through national and international channels through which the sтв supports sustainability efforts of the involved destinations, tourism providers, and nature parks. Supported activities include regular announcements of the certificate recipients on the www.slovenia.info portal and related social network campaigns, their participation in fairs, PR announcements and materials, study trips for journalist and agents, etc. Special media attention was given to the country and its GSST certification project at the гтв Berlin 2017 event, where the sтв was announced as the winner of the National Geographic World Legacy award in the category of Destination Leadership. The category assesses the best environmental practices, the protection of natural and cultural heritage, the impact on the local community, and the education of travelers in the field of sustainable tourism.

\section{Methodology}

Slovenia has a long history of promoting tourism innovation, which in recent years has been further stimulated by promoting sustainable development. In promoting innovation in tourism, the sтв and the Ministry of Economic Development and Technology have financed activities to promote and stimulate innovation in tourism since 2004 (Križaj \& Zakonjšek, 2011).

The main promotional activity is the annual national award for the most innovative tourism products, known as the Sower ('Sejalec' in Slovenian), which was founded in 2006 by the Bank of Tourism Potentials in Slovenia (втPS) portal. втPS has received UNWTO, OECD, and EU acknowledgements for its systematic promotion of innovation in tourism. In 2009, an additional tender for the most promising tourism ideas (known as Creator; 'Snovalec' in Slovenian) was introduced. In recent years, more than 50 tourism products have been granted one or both awards.

In cooperation with the sтв, the authors of this manuscript visited a select group of recipients of Creator and Sower award and Slovenian Green Certificates to identify challenges and innovations relating to the implementation of sustainability practices. Prior to these visits, the sтв sent invitations to the recipients of the Creator and Sower awards and to the Slovenian Green Certificate recipients. In the invitation, it was mentioned that the authors will visit interested tourism providers in Slovenia and will carry out short individual development workshops aimed at addressing sustainable development and innovation challenges faced by tourism providers in their every- 


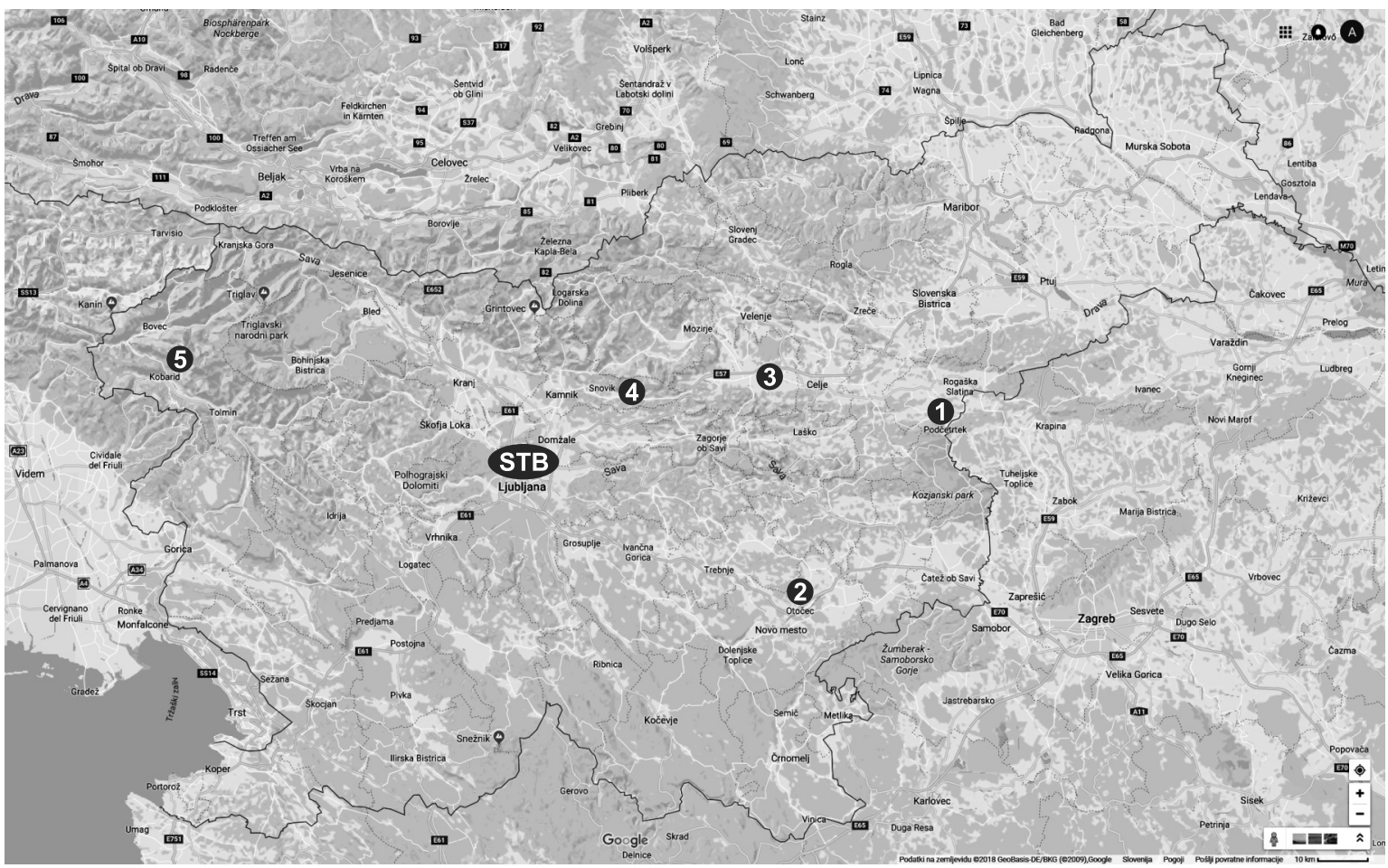

Figure 1 Locations of the Selected Tourism Providers (1-5) and Slovenia Tourist Board (s т в)

day business operations. Altogether, eleven tourism providers from all over Slovenia responded to the invitation, of which, due to resource constraints, the authors could choose and visit only five businesses (see Figure 1).

The Ortenia Apartments ( 1 ) is located in Podčetrtek (https://www.ortenia.com), near one of the numerous Slovenian spa resorts with a long tradition, on the border with Croatia (Ortenia Apartments, 2018). They market themselves as the first eco-friendly apartments in Slovenia, designed using the principles of innovative sustainable construction. Podčetrtek lies in the culturally and historically rich province of Kozjansko, situated close to a monastery from the 16th century, and has many opportunities for recreation in nature through a network of hilly and mountainous roads. The apartments are privately owned; the owners have recruited staff who run the entire operation of six accommodation units of a higher price/quality range. The Ortenia Apartments has received the Green Globe certificate and Slovenia Green Accommodation certificate.
Matjaž Pavlin, owner of Matjaž Homestead (2) in the village of Paha (http://www.matjazeva-domacija .si) has been the longtime owner and director of a renowned travel agency in the nearby city of Novo mesto, the urban centre of the Dolenjska region. Close to the homestead is a large spa centre, surrounded by the hilly landscape along the Krka River and its tributaries. There are numerous opportunities for tourism activities among the many vineyards that give the landscape its historical, geographical, and culinary mark. Matjaž Pavlin has received four Sower awards for his tourism projects.

The Green Gold beer fountain (3) was built in the middle of the city/municipality of Žalec (https://www .beerfountain.eu), which has been regarded as the centre of the Slovenian hops industry since the end of the 19th century. When Slovenia was still part of the Republic of Yugoslavia, hop collectors from all its republics then gathered in Žalec for commerce. Žalec was not a significant tourist centre before the appearance of the beer fountain. Since then, diversified tourism facilities and services have been developing 
rapidly, connected to the story of the beer fountain as well as stories of the nearby museum of hops and brewery industries built in 2009. This well-visited fountain, the first of its kind in the world (according to the owners) has received the Creator and Sower awards and is being mentioned in global media.

The Spa Snovik (4) lies in the green valley between Kamnik and Vransko (http://terme-snovik.si), on the threshold of the Kamnik-Savinja Alps. On approximately $1000 \mathrm{~m}^{2}$, the spa centre offers indoor and outdoor thermal pools, saunas, massages, and a restaurant. For guests staying on a longer holiday, they offer a four-star apartment complex with 370 beds. Activities in the surrounding area include hiking, biking, walking, and golf. Organic farms and baroque churches can also be seen in the vicinity. Spa Snovik is the recipient of the EU Ecolabel and Slovenia Green Accommodation Certificate.

The Eco Camp Koren (5) is located in the vicinity of Kobarid (http://www.kamp-koren.si), on the bank of the emerald-green Soča River, which is in its upper reaches and one of the five best-preserved natural rivers in the European Alps. The camp's visitors - settled in tent sites, camper and caravan sites, or eco chalets - mainly enjoy diverse adrenaline activities along the river bank, on the rapids of the river or surrounding natural climbing walls or explore unspoiled nature on hiking and biking tours or during fly fishing trips. Near the camp, the Soča river creates a short, scenic canyon, and the river's vast and scenic gravel beds are located close to the camp. In addition to that, tourists can visit the waterfalls of the Kozjak brook and the extensive restored front line from the 1st World War. Kobarid is also the location of a World War I Museum, which is considered one of the best of this kind in Europe. Camp Koren is the recipient of the EU Ecolabel and Slovenia Green Accommodation Certificate.

The authors visited the above-mentioned five tourism providers and conducted semi-structured interviews in which they analyzed the topics described further below. The beginning of the conversation was left to the tourist provider to present their product services and facilities, as well as challenges in any form, and then the authors led a systematic discussion covering the key research questions related to sustainability and innovation in tourism:

1. What were the environmental aspects of their sustainable operation?

2. What were the social responsibility aspects of their sustainable operation?

3. What were the economic aspects of their sustainable operation?

4. Did they face any challenges in the area of sustainable development and certification?

5. In their opinion, what is the added value of sustainable engagement?

6. How would they access their sustainable benchmarking with direct and indirect competition?

7. Which opportunities do they see in adopting and developing sustainable innovations and improvements?

Semi-structured interviews were conducted to determine the current sustainability performance gaps among each of the five tourism providers based on the environmental, social, and economic dimensions. As a triangulation measure, the interview findings were shared with the companies for their feedback and verification. Qualitative data received from the interviews with the five businesses were evaluated to obtain a general profile of the sustainability efforts and innovations of these companies and to identify the main challenges faced by them in the area of sustainability operations. The following sections provide a detailed description of the study's findings.

\section{Results and Discussion}

Promoted as the first eco-friendly apartments in Slovenia, the Ortenia Apartments utilized the principle of innovative sustainable construction and design, energy and water conservation efforts, and the use of organic fabrics and cosmetics to implement environmental sustainability within their operations. The plants surrounding the apartments were saved from the old garden of the house that stood at the site prior to the construction of the apartments, and fruit from some of the plants are used for making jams served to the apartments' guests. A key indicator in most 
tourism ecolabeling certifications is the usage of paper - it was observed that paper usage by the apartments was relatively higher compared to the other cases. For example, the management still relied on paper for guest food order/request forms, bathroom towels, etc., and these were not recycled after use. In the dimension of social sustainability, no extensive efforts were in place to address local needs and to engage with the local community. With regards to economic sustainability and contributions to the local economy, the apartments hired some staff from the area and provided its guests with discount coupons to promote some of the restaurants in the area. Additionally, it was noted that the apartments provided local wines and fresh tea (leaves), from a monastery located in the neighbourhood, to its guests.

The Matjaž Homestead's main environmental sustainability effort focused on the use of recycled wood and household furnishings for the construction of cottages and farmhouses, highlighting the traditional farmer views regarding the interconnectedness between farm life and the surrounding environment. With regards to social sustainability performance, it became clear that the Homestead was committed to promoting local wine and food and had a guest informational video to illustrate the culinary distinctions of the region. In addition, the Homestead was involved in several local initiatives, such as the restoration of historic buildings (e.g., local churches, farmhouses), the introduction of farm voluntourism, etc., which sometimes extended beyond the scope of tourism development, and related more to the broader context of regional community development and engagement. From an economic sustainability perspective, the Homestead is part of a larger initiative to create a network of local value chains including private wine cottages and farms by utilizing a scattered development model to stimulate the regional economy.

The Fountain of the Green Gold, the first beer fountain in the world, aligned well with the preservation of the hops industry in the region. Other than this connection to the environment, no specific initiatives relating to environmental sustainability, i.e., conservation and protection, were observed. In the dimension of social sustainability, the beer fountain has been instrumental in stimulating engagement between the local municipality, residents, and tourists. Since its creation, the beer fountain and surrounding gardens has become a local gathering place of cultural significance and has instilled a sense of pride among the residents of the community. In a region where hops production is an essential part of the local economy but hops farms are not utilized to their full production capacity due to external economic factors (particularly market competition), the beer fountain has contributed to the area's economic sustainability, by boosting the local economy, particularly in the neighborhood and around the main square on which the fountain is located. For example, the Open Kitchen programme connected with the fountain has promoted new opportunities for local entrepreneurs connecting the guest dining experience with the local hops culture.

The Spa Snovik's approach to environmental sustainability is emphasized through their stated commitment to nature-friendly operations, with a particular focus on reducing energy consumption. The resort was created based on the underlying principle of energy conservation and use reduction. For example, electricity is disconnected from every apartment in the resort when the space is not being used by the guest(s). Additionally, the spa has implemented onsite guest education programs for generating environmental awareness, such as planting of local trees and herb gardens (for guest use) along with markers to identify the flora and naming of apartment blocks in the resort based on the endemic trees of the area. In terms of social sustainability, it is essential to acknowledge that the resort idea originated from a local entrepreneur whose main goal was to integrate the resort with the community. To that effect, local community members have reduced-fee access to the resort's amenities, including spa, pools, and recreational facilities. Furthermore, the spa's apartments showcase the region's heritage and culture through locally-made furnishings and vintage photographs of the area's residents. The spa's efforts in supporting economic sustainability were observed through their local hiring practices and purchase of produce from local farmers only. While the spa has been involved in some commercial projects 
with the locals (such as the spa's guests attending community festivals jointly organized by the spa and local residents), these efforts have not yet reached their full potential in terms of stimulating the local economy.

The stated aim/virtue of Eco Camp Koren, the first eco-friendly camp in Slovenia, is the respect of nature and fellow human beings. The camp clearly addressed environmental sustainability throughout most of its operations, including design and construction, energy conservation, environmental management, guest and community education, and agriculture. The camp's efforts in social sustainability include spearheading municipal initiatives in collaboration with other local tourism providers to boost the economy and improve work conditions in the industry, sharing tourism know-how and information from national level meetings among local businesses, engaging guests with community members through joint activities such as camping skills workshops, organizing camp dinners created by local chefs using local ingredients, inviting the area's residents to join camp guests at concerts and events held at the camp, etc. From the perspective of economic sustainability, the camp employed local students, partnered with local 'adrenaline' sports activity providers to offer camp packages and promoted their services through the camp's information services, sold local products through the souvenir shop, and hosting local sports competitions at no cost to the participants.

While all five businesses examined in this study were recipients of the $\mathrm{s}$ т B's Creator/Sower award and/ or Slovenian Green Certificate, it became apparent that their respective sustainability performances varied greatly along environmental, social, and economic dimensions. Although most of the businesses were able to reasonably integrate environmental and economic sustainability criteria within their respective management and operational frameworks, only a few were able to satisfactorily position their initiatives towards supporting social sustainability and community development. Overall, none of the businesses had articulated long-term plans for addressing critical social sustainability indicators such as supporting and promoting cultural and heritage conservation, maximizing cultural and heritage benefits, minimizing negative cultural and heritage impacts, adopting codes of cultural behavior for guests, providing in-kind or philanthropic assistance for local, community-based social empowerment projects, advocacy groups, etc. During the interview phase, the authors also observed that the concept of social sustainability was interpreted differently by each of the five businesses and they were unable to deliberately operationalize this dimension within their respective sustainability-related efforts in an effective manner with future positive implications for the local community. Some businesses expressed interest in learning more about social sustainability and how to incorporate this dimension within their operations. These businesses indicated that since they had received the Slovenian Green Certificate from the STB, it would be beneficial if the sт в could also provide technical know-how (including legal guidance), training and workshops to assist them in operationalizing social sustainability and implementing community development/engagement projects.

The sustainability performance analyses of each of the five tourism businesses certified by the s т в revealed that there was a consensus among the establishments regarding guidelines/indicators for achieving environmental and economic sustainability, although some of them had long-term systems in place to improve their initiatives related to these dimensions, whereas others exhibited a short-term/reactive approach to these sustainability goals. The most notable variances/gaps in the sustainability performances of the businesses were notably observed in their levels of commitment to implementing long-term social sustainability initiatives. From a CSR standpoint, it would be prudent for the s т в to determine strategies and solutions for addressing this gap in the social sustainability performance of the tourism businesses which have been awarded the Slovenian Green Certificate. Establishing clear social sustainability goals as well as trackable and measurable criteria and respective indicators that connect the s т B's commitment to Slovenia's longterm community development agenda would not only help increase social sustainability performance among the sтв's certificate recipients (and non-recipients), but could also position the country as a green tourism leader with a social-responsibility commitment to its citizens and visitors. 
The companies were also asked why and how their tourism product offers inspiration to other innovators of sustainable tourism and about what problems the national stakeholders, such as the sтв and municipalities, should be cautioned. All five companies indicated that they are quite regularly mentioned as good cases (because of the prizes and labels they received or due to their diversified tourism offering). Guests of the Ortenia Apartments are often interested in the building, entirely designed with natural materials. Many of them come to check the premises since they want to build their own dwelling in a similar manner. Matjaž Pavlin mentions that he provides a 'before-then situation' presentation to many visitors, showing how he started rebuilding at the beginning when he bought the farm and preserved the heritage of the farm by keeping the old buildings rather than demolishing them. According to him, the groups are enthusiastic and inspired by his presentation to transfer his approach to their home environment. The Green Gold Beer Fountain managers see their greatest achievement in the fact that they succeeded with an idea that seemed unusual and initially had many opponents and skeptics. Now, they are an example to many entrepreneurs and individuals that tourism innovations can be realised if there are sufficient desire and interest among stakeholders. Both Spa Snovik and Eco Camp Koren inspire other innovators with top-notch nature conservation approaches that include Iso standards, ecolabels, renewable heating approaches, energy consumption reductions, employing mostly locals, etc. Both already have new development plans from incorporating traditional holistic treatment methods to new green accommodations, fitness, and meeting space/convention investments.

Although all companies agreed that in the previous year, the promotion of natural and ecological tourism offerings has grown, they felt that there is room for improvement. The state (and especially the municipalities in which certified tourism providers are located) would, in their opinion, still have to do more to emphasize and promote the sustainability movement. This would, according to Ortenia Apartments, additionally increase the customers' and providers' awareness regarding contemporary sustainability is- sues. Matjaz Pavlin, in contrast, thinks that he has never sought excessive help from the state and, therefore, it cannot help or disappoint him. The Green Gold Beer Fountain had a different state-related experience. Once the first acknowledgements for innovation were received by the beer fountain from outside Slovenia and their town, the local environment became more perceptible to this innovation. It would be difficult for them to suggest what more the state could do. In their opinion, the Sower and Creator awards that they have received are indeed examples of positive incentives, which helped to convince their local stakeholders that they are on the right track. When Spa Snovik became the first green provider of Slovenian tourism ten years ago, they tried to encourage and seek out related providers. After a decade of efforts by Spa Snovik (as well as interventions by the sтв), the number of such sustainability-oriented partners has started to rise rapidly. Similarly, Eco Camp Koren has been a local sustainability champion for many years, but hopes for their entire destination to be certified aside on GSST so that the company can be considered as a sustainable tourism provider in a certified sustainable destination.

\section{Conclusion}

With the growing trend of businesses obtaining ecolabels within the tourism sector (Margaryan \& Stensland, 2017) and the rapid 'greening' (Vaccaro \& Patiño, 2010) of the world's largest industry, a significant concern is the potential utility of eco-certifications to effectively address the social responsibility dimension of sustainable tourism. The results of this study indicated that sustainability performances of eco-labelled/ecocertified tourism businesses vary greatly along environmental, social, and economic dimensions. Although tourism businesses are generally prepared to implement environmental and economic sustainability initiatives as part of their regular operations, there is an overall lack of consensus with respect to the adoption of social sustainability owing to the lack of clear parameters and guidelines for operationalizing the performance indicators associated with the criteria established by ecolabeling organizations (such as the sтв). Furthermore, variations among eco-labelled 
tourism establishments in terms of their levels of engagement in and commitment to social sustainability is also, perhaps, correlated with the perceptions of owners, managers, and staff regarding the 'bottomline' effect of adopting measures to boost the business' sustainability performance along this dimension. To address social sustainability performance gaps among tourism businesses, destination management organizations and tourism governing bodies responsible for awarding eco-certifications will need to identify and articulate specific, measurable, and trackable social/community development targets and goals which could be satisfactorily achieved by the various sectors of the industry.

In Slovenia, awareness of sustainable development concepts in tourism is rapidly gaining momentum, which means that companies are realizing the business sense in consistently offering (mostly environmental and economic) sustainable tourism products and experiences. Although in the beginning, energyefficient infrastructure, as well as green services, are more expensive, Snovik Spa calculations showed that their returns-on-investment in such infrastructure were realized sooner than anticipated (Zlatoper, personal communication, November 2017). According to all of five businesses, the company that is presented as a green provider in the tourist market has increasingly more opportunities to acquire high-quality partners and guests with higher levels of loyalty and spending capacity.

While the sustainable tourism innovation activities are still ongoing in Slovenia, it is highly likely that the majority of tourism providers in the country will start to adopt greater standards for environmental and economic sustainability, although the next focus of tourism companies (especially among early adopters) needs to be directed towards social sustainability in tourism, in the coming years.

\section{References}

Buckley, R. (2013). Social-benefit certification as a game. Tourism Management, 37, 203-209.

Chatterji, A. K., \& Toffel, M. W. (2010). How firms respond to being rated. Strategic Management Journal, 31(9), 917945 .
Dawkins, C. (2010). Beyond wages and working conditions: A conceptualization of labor union social responsibility. Journal of Business Ethics, 95(1), 129-143.

Dziuba, R., (2016). Sustainable development of tourism: EU ecolabel standards illustrated using the example of Poland. Comparative Economic Research, 19(2), 111-128.

Font, X. (2002). Environmental certification in tourism and hospitality. Tourism Management, 23(3), 197-205.

Honey, M., \& Rome, A. (2000, November). Ecotourism and sustainable tourism certification. Draft report prepared for the ecotourism and sustainable tourism certification workshop, New Paltz, NY.

Križaj, D., \& Zakonjšek, T. H. (2011). National mechanism for spurring innovation in Slovenian tourism. Academica Turistica, 4(1), 103-110.

Lai, C., Chiu, C., Yang, C., \& Pai, D. (2010). The effects of corporate social responsibility on brand performance: The mediating effect of industrial brand equity and corporate reputation. Journal of Business Ethics, 95(3), 457-469.

Margaryan, L., \& Stensland, S. (2017). Sustainable by nature? The case of (non)adoption of eco-certification among the nature-based tourism companies in Scandinavia. Journal of Cleaner Production, 162, 559-567.

Middleton, V., \& Hawkins, R. (1998). Sustainable tourism: A marketing perspective. Oxford, England: ButterworthHeinemann.

Mihalic, T. (2000). Environmental management of a tourist destination: A factor of tourism competitiveness. Tourism Management, 21(1), 65-78.

Morgan, R. (1999). A novel, user-based rating system for tourism beaches. Tourism Management, 2o(4), 393-410.

Sandhu, S., Ozanne, L., Smallman, C., \& Cullen, R. (2010). Consumer driven corporate environmentalism: Fact or fiction? Business Strategy and the Environment, 19(6), 356-366.

Sandve, A., Marnburg, E., \& Ogaard, T. (2014). The ethical dimension of tourism certification programs. International Journal of Hospitality Management, 36, 73-80.

Sasidharan, V. (2017). Social sustainability gaps in tourism. In AIRTH encyclopedia of Innovation in tourism and hospitality. Retrieved from http://www.airth.global/ depositview.aspx?dpid=7543\&lng=en

Slovenian Tourist Board. (2017, 31 January). 2016 - another record year for Slovenian tourism. Retrieved from https: //www.slovenia.info/en/press-centre/press-releases/ 7184-2016-another-record-year-for-slovenian-tourism

Vaccaro, A., \& Patiño, D. (2010). Corporate transparency and green management. Journal of Business Ethics, 95(3), 487-506. 
$\mathrm{Wu}, \mathrm{J}$. (2010). The impact of corporate supplier diversity programs on corporate purchasers' intention to purchase from women-owned enterprises: An empirical test. Business and Society, 49(2), 359-380.

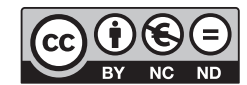

This paper is published under the terms of the Attribution- NonCommercial-NoDerivatives 4.0 International (CC B Y-NC-ND 4.0) License. 